\title{
UROPEPSIN EXCRETION BY MAN. I. THE SOURCE, PROPERTIES AND ASSAY OF UROPEPSIN ${ }^{1,2}$
}

\author{
By I. ARTHUR MIRSKY, STANLEY BLOCK, STANLEY OSHER, \\ AND ROBERT H. BROH-KAHN \\ (From The May Institute for Medical Research, The Jezish Hospital, and the Departments of \\ Medicine and Psychiatry, University of Cincinnati College of Medicine, Cincinnati)
}

(Received for publication August 16, 1948)

The conventional method used to study gastric secretion and activity involves the withdrawal and examination of specimens of gastric juice. Such a procedure subjects the average patient to considerable physical and emotional stresses. Further, the repeated collection of samples of gastric juice from a great number of individuals over a prolonged period of time presents many practical difficulties. It would, therefore, be advantageous to possess a means for the study of gastric activity which would have none of the disadvantages involved in the withdrawal of the gastric contents. During the course of studies designed to develop some technique for this purpose, we investigated the excretion of uropepsin, a pepsin-like enzyme in the urine.

The presence of an enzyme in the urine, with proteolytic activity at strongly acid reactions, was first demonstrated by Brucke (1). Since that time occasional investigators have reported information concerning the nature of this substance, its source, and the factors controlling its appearance in the urine. Unfortunately much of the early work in this field was accomplished with the aid of methods of a questionable degree of accuracy. In particular this is true for the procedures utilized for the determination of the activity of this substance. Accordingly, much of this work, which has been summarized in an excellent review by Bucher (2), requires confirmation. More recent studies by Farnsworth, Speer and Alt (3) and by Bucher (2), have reopened this field of inquiry and have contributed additional knowledge concerning uropepsin.

Certain facts appear to be well-established. Uropepsin is not found in the urine of gastrectomized

1 Presented in part before the American Physiological Society, Atlantic City, March, 1948.

2 Aided in part by a grant from the Mental Hygiene Council, Research Grants Division of the U.S. Public Health Service. dogs (4), gastrectomized cats (5) or patients with the achylia gastrica of pernicious anemia (3). Presumably, therefore, the function of the peptic cells of the gastric mucosa is essential for the formation of uropepsin. Consequently, it is possible that some correlation might be found to exist between gastric activity and the amount of uropepsin in the urine. Towards that end we considered it desirable to define quantitatively such relationships as could be observed between any aspect of gastric function and the excretion of uropepsin. The studies of Bucher (2) and Farnsworth et al. (3) have already noted certain of these correlations. In the present series of studies, an attempt is made to define further certain of the factors that regulate the excretion of uropepsin by man.

\section{METHODS}

Methods for the estimation of uropepsin have been described by both Bucher (2) and Farnsworth et al. (3). These depend upon incubation of a sample of urine with a denatured hemoglobin substrate (6) over periods of either 60 minutes or 18 hours (3) and the subsequent determination of the extent of proteolysis by the Folin and Ciocalteu procedure (7). Since both the hemoglobin substrate and the urine itself contain substances which react with the Folin-Ciocalteu reagent, the amount of acid-soluble "tyrosine-like" material present prior to incubation was determined after incubation of an heatinactivated specimen of urine with the substrate. The difference between these two values was utilized as the index of uropepsin activity.

Such methods involve certain objectionable features. In the first place, although Bucher presented data which tended to indicate that the addition of urines of widely different $\mathrm{pH}$ to the acid hemoglobin substrate did not lead to inaccurate results, it is not difficult to demonstrate that the addition of $1 \mathrm{ml}$. of unadjusted urine to $5 \mathrm{ml}$. of the standard hemoglobin substrate does result in changes in the final $\mathrm{pH}$ of the mixture, changes which are dependent on the composition and reaction of the urine specimen itself. The desirability of measurement of enzyme activity at a constant $\mathrm{pH}$ is too well known to require further comment. In the second place, although heat-inactivation of urine destroys its uropeptic 
activity, the use of such a specimen as a control may lead to an incorrect estimation of the uropeptic activity since some specimens of urine have been found to undergo an increase in their content of "tyrosine-like" substances on heating. Although this phenomenon has not been noted with either regularity or frequency, its occasional appearance vitiates the accuracy of such a procedure.

In order to circumvent such objections, the following procedure was utilized. An aliquot of $20 \mathrm{ml}$. of urine was adjusted to $\mathrm{pH} 1.5$ and made up to a total volume of $25 \mathrm{ml}$. with distilled water. One $\mathrm{ml}$. of the adjusted urine, representing $0.8 \mathrm{ml}$. of the undiluted urine, was incubated with $5 \mathrm{ml}$. of the denatured hemoglobin substrate at $\mathrm{pH} 1.5$ as described for the estimation of pepsin (6) except that the temperature during incubation was maintained at $37^{\circ} \mathrm{C}$. At the end of the prescribed period of incubation, the reaction was stopped by the addition of trichloracetic acid and the concentration of acid-soluble "tyrosine-like" substances in the filtrate was determined by the Folin-Ciocalteu method adopted to use of a spectrophotometer. The concentration of chromogenic substances originally present in both urine and substrate was determined by the separate addition of $1 \mathrm{ml}$. of the adjusted, diluted urine and $5 \mathrm{ml}$. of the hemoglobin substrate directly to trichloracetic acid. The difference in readings obtained from the incubated and unincubated samples was taken to indicate the increase in concentration of chromogenic substances due to proteolysis.

\section{RESULTS}

It was found possible to shorten materially the times of incubation used by both Bucher and Farnsworth et al. With most urines, incubation for only ten minutes produced a significant degree of proteolysis. The use of such a short period of incubation offers definite practical advantages. However, owing to the limits of accuracy of the analytical procedure, changes during incubation of only $2 \%$ transmission could fall within the limits of experimental error. Whenever such small changes were obtained, the incubation was repeated for 30 minutes. If the low degree of apparent proteolysis was due solely to the relative inaccuracy of the technic, use of the longer period of incubation failed materially to produce an increase in such values. On the other hand, if the low results obtained from a ten-minute period of incubation were actually due to a low degree of uropepsin activity, values approximately three times as great as those previously found were obtained by means of the 30-minute period of incubation. These higher values were then divided by three in order to reduce them to the basis of a tenminute period of incubation. The justification for

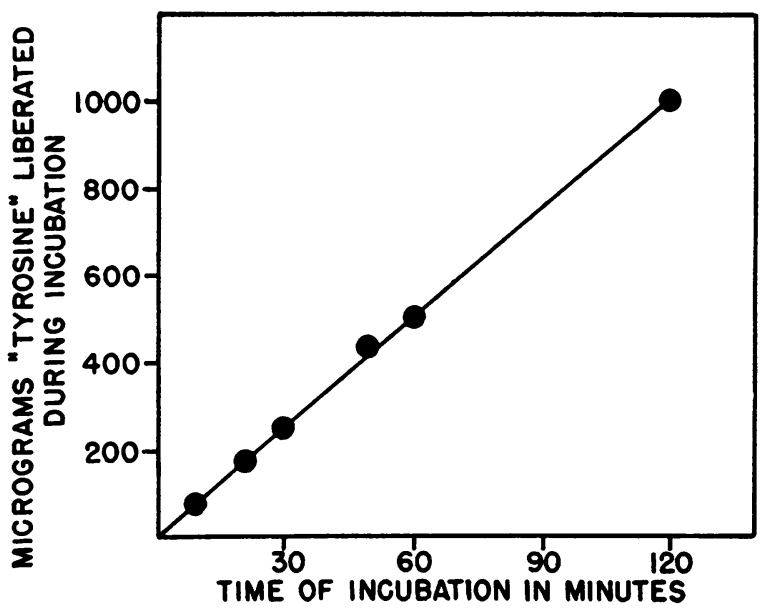

Fig. 1. EfFect of Incubation Time on Uropepsin Activity

The results illustrate the amounts of "tyrosine" released by $1 \mathrm{ml}$. of adjusted urine during different incubation periods.

such a procedure is illustrated in Figure 1 which demonstrates that the degree of proteolysis produced by uropepsin increases in a linear manner with time throughout a two-hour period of incubation.

In view of the above findings, we have routinely based all of our calculations of activities on a tenminute period of incubation. For the sake of convenience, an arbitrary unit of activity of uropepsin has been selected, which is defined as that quantity which, during a ten-minute incubation in the standard assay, releases $1 \mathrm{mg}$. of "tyrosine-like" substance. To derive this unit, the results obtained from the spectrophotometric assay are recalculated in terms of the activity contained in $1 \mathrm{ml}$. of undiluted urine. For example, if $1 \mathrm{ml}$. of the adjusted, diluted urine has been found to release $40 \gamma$ of "tyrosine" during the ten-minute period of incubation, $50 \gamma$ would have been released by each $\mathrm{ml}$. of the undiluted urine. Accordingly, every $20 \mathrm{ml}$. of urine would contain 1 unit of uropepsin.

In order to proceed with the interpretation of the amount of uropepsin as it is assayed in urine specimens, it is of paramount importance to be able to demonstrate that such activity represents the actual quantity of uropepsin as it was originally excreted in the urine. If the activity undergoes gradual decreases due to the instability of the enzyme or if other substances present in the urine partially inhibit its activity, assays on specimens of 
urine may fail to yield accurate data concerning the amount of uropepsin actually excreted by any particular subject. Experiments were therefore undertaken to investigate the problem of the stability of this enzyme and to detect the presence in urine of any inhibitory substances which might mask some fraction of the total activity.

Bucher (2) has demonstrated the stability of uropepsin activity in urine during four-day periods of storage at room temperature and for at least two weeks during standing in the refrigerator. Our own results completely confirm such findings as is illustrated by Table I. Furthermore, the addition of toluol to the urine fails to affect the activity and insures its stability during storage at both room temperature and in the refrigerator. As a result we have adopted as routine the collection of speci-

TABLE I

Stability of uropepsin

\begin{tabular}{c|c|c|c|c}
\hline \hline \multirow{2}{*}{$\begin{array}{c}\text { Duration of } \\
\text { storage }\end{array}$} & \multicolumn{2}{|c|}{ Conditions of storage } & $\begin{array}{c}\text { Toluol } \\
\text { added }\end{array}$ & $\begin{array}{c}\text { Peptic } \\
\text { activity }\end{array}$ \\
\cline { 2 - 5 } & Room temp. & $\begin{array}{c}\text { Cold room } \\
\left(3^{\circ}-5^{\circ} \text { C. }\right)\end{array}$ & & \\
\hline days & & & & \\
0 & & & No & 78 \\
0 & & & Yes & 74 \\
1 & $\mathrm{x}$ & & Yes & 82 \\
1 & & $\mathrm{x}$ & Yes & 75 \\
7 & $\mathrm{x}$ & & Yes & 78 \\
14 & $\mathrm{x}$ & & Yes & 73 \\
28 & & $\mathrm{x}$ & Yes & 74 \\
\hline
\end{tabular}

Peptic activity expressed as micrograms "tyrosine" released by $1 \mathrm{ml}$. of urine during standard assay.

mens of urine in containers to which sufficient toluol had been added and have stored them at ice box temperature $\left(3^{\circ}-5^{\circ}\right.$ C. $)$ in such instances in which assays could not be performed on the day of their collection. The toluol was always removed prior to assay.

The stability of uropepsin under these conditions has certain practical implications since it has been found feasible to collect specimens of urine in other cities and to have them shipped to our laboratory for assay. For this purpose, a specimen of urine is collected as described, its total volume measured and notation is made of the period of its collection. An aliquot (approximately $25 \mathrm{ml}$.) is placed in a large test tube, covered with toluol and sent to our laboratory for examination.

Efforts to demonstrate the presence of uropepsin
TABLE II

Effect of dialysis on activity of uropepsin

\begin{tabular}{c|c|c}
\hline \hline \multirow{2}{*}{ Urine } & \multicolumn{2}{c}{$\begin{array}{c}\gamma \text { "Tyrosine" released by } 1 \mathrm{ml} \text { urine } \\
\text { during standard assay }\end{array}$} \\
\cline { 2 - 3 } & Experiment A & Experiment B \\
\hline $\begin{array}{l}\text { Before dialysis } \\
\text { After dialysis }\end{array}$ & 58 & 75 \\
\hline
\end{tabular}

Urines dialyzed overnight against running ice-cold water in Visking membranes. Results after dialysis recalculated to take account of dilution during dialysis.

inhibitors in urine have not been successful. The possible presence of an inhibitor of low molecular weight was ruled out by the results illustrated in Table II which indicate that dialysis of the urine failed to alter its activity, a finding which, at the same time, confirms the presumed protein-like nature of the enzyme itself. Washing with chloroform has also been described as an effective method for the removal of substances that inhibit the activity of some proteolytic enzymes. Such a procedure failed to affect the activity of uropepsin. Furthermore, since active uropepsin is believed to resemble or to be identical with gastric pepsin, substances which inhibit uropepsin should probably also inhibit gastric pepsin. In order to investigate this possibility, the effect of the addition of various specimens of urine on the activity of a solution of gastric pepsin of known potency was determined. Such results are found in Table III and indicate that urine contains no substances that inhibit the activity of pepsin. The lack of inhibitor substances and the stability of uropepsin indicate that the methods used in this study determine the actual amount of uropepsin excreted. The uropep-

TABLE III

Effect of urine on activity of gastric pepsin

\begin{tabular}{|c|c|c|}
\hline \multirow{2}{*}{ Enzyme preparation } & \multicolumn{2}{|c|}{$\begin{array}{l}\text { Peptic activity of enzyme } \\
\text { preparation* }\end{array}$} \\
\hline & Experiment $\mathrm{A}$ & Experiment $B$ \\
\hline $\begin{array}{l}\text { Urine alone } \\
\text { Gastric pepsin } † \text { alone } \\
\text { Urine and gastric pepsin } \ddagger\end{array}$ & $\begin{array}{r}87 \\
317 \\
400\end{array}$ & $\begin{array}{l}120 \\
401 \\
541\end{array}$ \\
\hline $\begin{array}{l}\text { \% Recovery of activity of } \\
\text { gastric pepsin in urine }\end{array}$ & 99 & 104 \\
\hline
\end{tabular}

* Activity expressed in terms of $\boldsymbol{\gamma}$ "tyrosine" released by $1 \mathrm{ml}$. enzyme preparation during standard assay.

$\dagger$ A dilute solution of Wilson 1:22,000 pepsin in water. $\ddagger$ A solution of the same concentration in urine. 
sin assays accordingly offer a valid procedure fòr the estimation of the amount of uropepsin excreted during a given period of time.

In previous studies on uropepsin, it has been assumed that the proteolytic activity of uropepsin at strongly acid reactions is proof of its pepsinlike nature. Nevertheless, although maximum activity of the enzyme is evident at lower $\mathrm{pH}$, considerable proteolytic activity can be demonstrated when the urine and substrate are incubated at $\mathrm{pH}$ 3.5. This latter reaction has been designated (6) as appropriate for detection and determination of catheptic activity. Furthermore, gastric juice is known to contain considerable quantities of enzymes with catheptic activity (8). Inasmuch as uropepsin presumably originates in the stomach, it might be postulated that some, if not all, of uropeptic activity is catheptic rather than peptic in nature.

However, it appears safe to assume that most, if not all, of the proteolytic activity of urine at $\mathrm{pH} 1.5$ may be attributed to the activity of a pepsin-like enzyme since cathepsins derived from animal tissues are known to be rapidly inactivated at this reaction (9) and since we have been able to demonstrate the stability of uropepsin over a 24-hour period at this reaction. A comparison of the $\mathrm{pH}$ activity

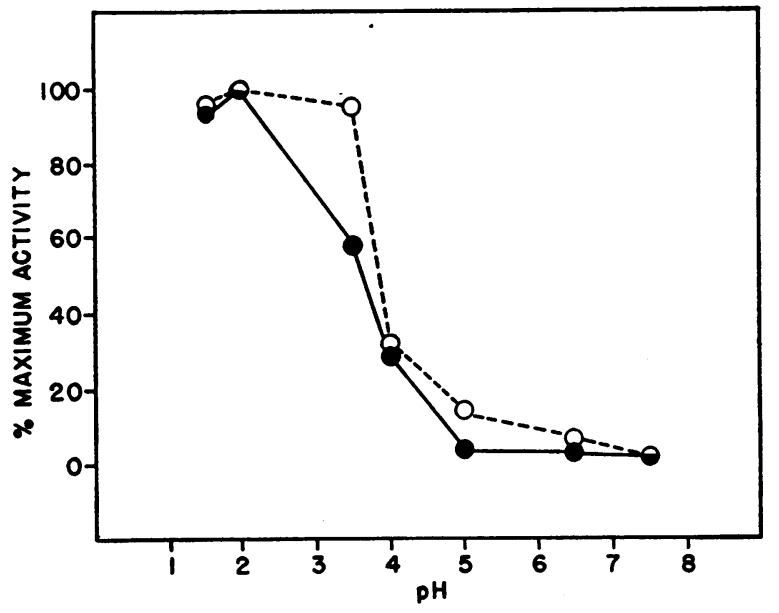

Fig. 2. Effect of pH on Activity of Uropepsin and Gastric Pepsin

Activity calculated in terms of amounts of "tyrosine" released by $1 \mathrm{ml}$. of urine or aqueous solution of $1: 22,000$ Wilson pepsin during ten-minute incubation periods. In every case, both enzyme solution and substrate were adjusted to indicated reaction. Closed circles represent gastric pepsin; open circles, urine. curves of uropepsin and of gastric pepsin is demonstrated graphically in Figure 2. For this purpose the $\mathrm{pH}$ activity curve of uropepsin was compared with the $\mathrm{pH}$ activity curve of a specimen of gastric pepsin diluted in urine from a patient with pernicious anemia (containing no uropepsin activity). The results reveal certain points of resemblance and of dissimilarity between the two curves. Uropepsin manifests considerably more activity at $\mathrm{pH}$ 3.5 than does gastric pepsin. Otherwise the two curves can be almost superimposed upon one another. Whether or not the high degree of proteolytic activity of urine at $\mathrm{pH} 3.5$ can be attributed to the presence of a catheptic enzyme has not yet been determined and must await examination of its action on some of the polypeptides demonstrated by Bergman et al. (10) to be useful for the identification of the type of enzyme involved. It would appear unlikely that much of the activity of urine at $\mathrm{pH} 3.5$ could be due to the presence of a catheptic enzyme since the activity decreases so abruptly even at $\mathrm{pH}$ 4.0.

By way of comparison, the $\mathrm{pH}$ activity curve of the cathepsin of gastric juice should be consulted (11). This activity curve was based on the degree of proteolysis of casein, instead of hemoglobin, and the effect of urine on this curve is unknown. Nevertheless, it would appear safe to conclude that uropepsin and pepsin resemble one another and are markedly dissimilar to gastric cathepsin in regard to their $\mathrm{pH}$ activity curves.

It is of interest to note that Freudenberg demonstrated some activity of gastric cathepsin at $\mathrm{pH}$ 2 and pointed out that the measurement of peptic activity at this $\mathrm{pH}$ cannot be accepted as an accurate method for the determination of the amount of pepsin present in gastric juice (11). Such a warning reemphasizes the importance of measurement of uropepsin at a constant $\mathrm{pH}$, preferably at $\mathrm{pH} 1.5$, particularly if uropepsin is to be interpreted solely as an excretion product of a pepsinlike enzyme.

It is possible to demonstrate that all of the proteolytic activity of urine at $\mathrm{pH} 3.5$ can be attributed to the excretion of a substance produced by the gastric mucosa. This was accomplished by examination of the proteolytic activity of the urine of gastrectomized patients and of patients with pernicious anemia. In every such instance, when no activity was noted at $\mathrm{pH} 1.5$ none was found at $\mathrm{pH}$ 


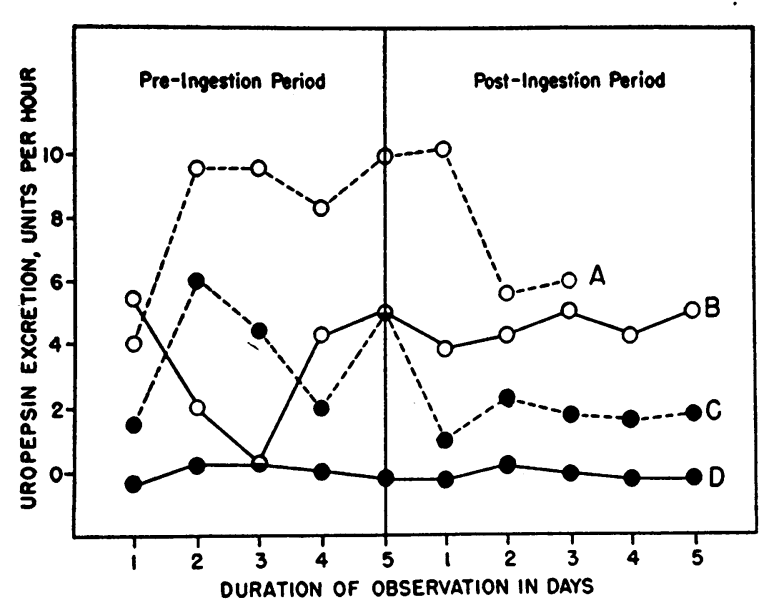

Fig. 3. Effect of Oral Ingestion of Pepsin on UROPEPSIN EXCRETION

Five grams of scale pepsin U.S.P. ingested by each subject at end of period corresponding to collection of urine for fifth day of observation. Urines were collected in each instance for the entire 24-hour period.

$A, B$, and $C$ represent uropepsin excretions of three healthy, adult male subjects. D represents uropepsin excretions of a patient with pernicious anemia.

3.5. Whereas such evidence does not constitute conclusive proof, it suggests that the proteolytic activity of urine at $\mathrm{pH} 3.5$ may be due to the presence of the same substance whose activity we determine at $\mathrm{pH} 1.5$ and which is considered to be uropepsin.

Controversies concerning the source of uropepsin have been discussed by Bucher (2). Obviously, if it originates in the stomach, it presumably must be transported to the kidney by the blood stream. The mode of entrance of the enzyme into the circulation and the form in which it enters the blood are still problematical. It is conceivable that pepsin may be reabsorbed into the blood stream after its secretion by the peptic cells into the lumen of the stomach. On the other hand, the enzyme may be absorbed into the blood directly from the secreting cells themselves without a preliminary secretion into the lumen. To test these hypotheses, gastric pepsin was fed to healthy adults, to patients with no uropepsin excretion (pernicious anemia) and to normal dogs (Figure 3).

When pepsin was fed to normal subjects already excreting appreciable amounts of uropepsin, no increases were noted in their uropepsin excretions beyond the limit of those fluctuations normally observed from day to day. On repeated occasions several patients with pernicious anemia ingested $\mathbf{5}$ grams of a potent preparation of pepsin. If as little as $0.1 \%$ of the amount of pepsin ingested eventually had been excreted into the urine, a very large quantity of uropepsin should have been excreted. Although the urine of such patients was collected for several days after the ingestion of the enzyme, at no time was it possible to detect an excretion of uropepsin by such individuals. Similarly, the administration of pepsin per os to dogs who normally excrete low amounts of uropepsin failed to result in an increase in these values.

In order to investigate the fate of pepsin after its introduction into the blood stream, dogs were

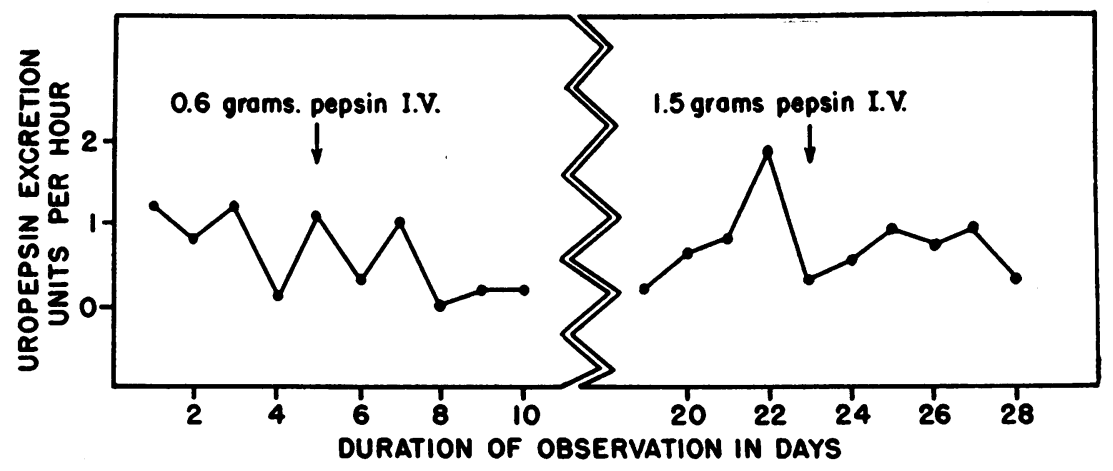

Fig. 4. Effect of Intravenous Injection of Pepsin on Uropepsin Excretion OF DOG

$1: 22,000$ Wilson pepsin injected intravenously on days indicated by arrows after end of periods of collection of urines on respective days. Results obtained from analysis of entire 24-hour urine output. 


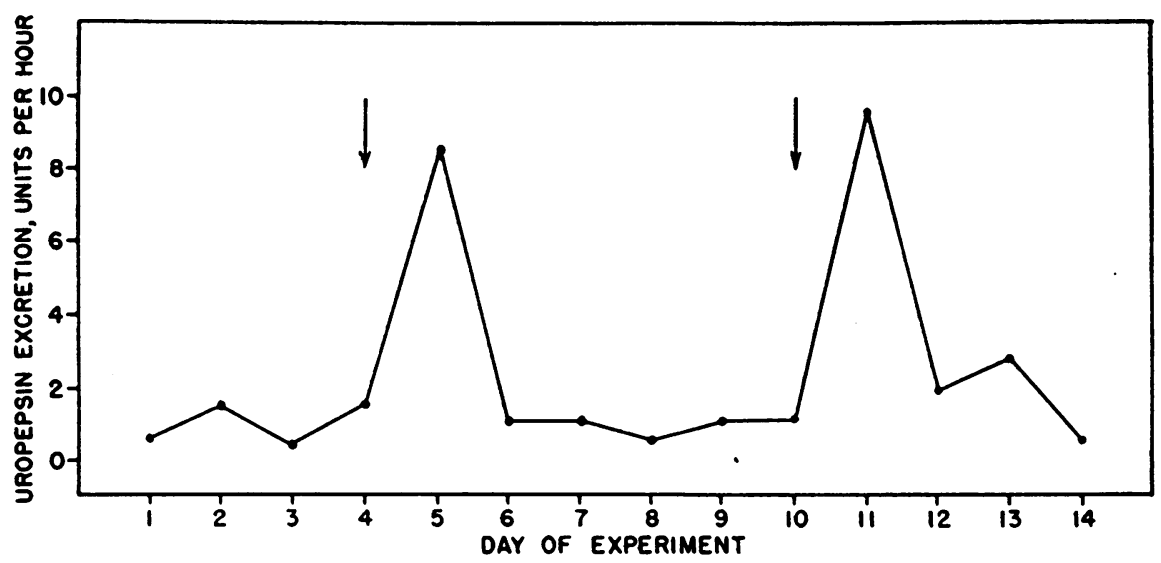

Fig. 5. Effect of Intravenous Injection of Pepsinogen on Uropepsin Excretion or DoG

Results obtained from analysis of entire 24-hour urine output each day. On days indicated by arrows, a crude pepsinogen solution, prepared as described in text, was injected intravenously at end of period of collection of urine for indicated day. Increases in excretion therefore occurred during a 24-hour interval following injection.

injected intravenously with as much as $80 \mathrm{mg}$. of pepsin per $\mathrm{kg}$. of body weight and their urine was collected for several days thereafter. Assay of such urines failed to demonstrate an increase in uropepsin excretion (Figure 4). In view of such results, it would appear that pepsin either is not absorbed from the lumen of the stomach into the blood stream, or if so, it is inactivated in the circulating blood and is excreted by the kidney in an inactive form.

Since the preceding results tend to indicate that pepsin is not responsible for the excretion of uropepsin, it became pertinent to investigate the possibility that pepsinogen might act as the precursor of uropepsin. Accordingly, a crude specimen of pepsinogen was prepared from swine gastric mucosa according to the methods outlined by Herriot (6). A quantity of this preparation was injected intravenously into a dog. Since the dog, as demonstrated above, fails to excrete large quantities of uropepsin and since it was demonstrated that intravascular pepsin is not excreted, the intravenous injection of pepsinogen into such an animal was considered as an ideal test for the solution of this problem.

The results obtained from this experiment are illustrated in Figure 5 which demonstrates the marked increase of uropepsin excretion after the intravenous injection of pepsinogen. Such results confirm the hypothesis that pepsinogen can be excreted in the urine if it once gains entrance into the blood stream.

\section{DISCUSSION}

Our data confirm earlier studies to the effect that an enzyme with peptic activity is normally present in human urine. Most, if not all, of the proteolytic activity in urine manifest at both $\mathrm{pH}$ 1.5 and $\mathrm{pH} 3.5$ can be attributed to the activity of a pepsin-like enzyme.

The experiments described herein suggest the source and nature of uropepsin. Lack of uropepsin activity in the urine of gastrectomized dogs (4), gastrectomized cats (2) and gastrectomized man, conclusively demonstrates that uropepsin is not found in the absence of the stomach. Furthermore, in the presence of an achylia gastrica, no uropepsin is excreted in the urine (3). It therefore may be concluded that uropepsin undoubtedly originates as the result of the peptic activity of the gastric mucosa. The possibility that such activity excites or activates the formation and secretion of uropepsin by another organ cannot be ruled out. Such an hypothesis, however, is not supported by sufficient evidence to warrant further consideration. Consequently, it is probably safe to assume that uropepsin is derived directly as the result of the function of the peptic glands in the gastric mucosa.

The peptic glands of the stomach secrete a proenzyme, pepsinogen, which undergoes autocatalytic conversion to active pepsin in the presence of the hydrochloric acid present in the lumen of the stomach (6). Since the normal organ contains considerable acid, most of the enzyme secreted into 
the stomach must be converted almost immediately to the form of pepsin. In the normal stomach, therefore, there is little opportunity for pepsinogen to exist for a period of time long enough to permit the absorption of appreciable amounts into the blood stream. This hypothesis receives support from our own observations that the oral administration of pepsinogen with or without a buffer failed to increase uropepsin excretion in the dog. Such results can be interpreted only by assuming either that pepsinogen cannot be absorbed from within the lumen of the stomach or else that it is converted too rapidly to pepsin which latter, as was already demonstrated, cannot act as a precursor of uropepsin. Furthermore, since pepsin is not excreted as uropepsin even after its intravenous administration, it seems certain that uropepsin cannot be derived from a peptic enzyme, once the latter has been secreted into the lumen of the stomach.

The above considerations induce one to regard favorably the hypothesis that uropepsin originates as a result of the secretion of an enzyme system from the peptic glands directly into the blood (2). Inasmuch as pepsin per se does not exist in the secreting glands, it appears probable that the immediate precursor of uropepsin must be pepsinogen which is absorbed directly into the blood stream from the secreting cells and so transported intravascularly to the kidney. Since the intravenous administration of pepsinogen does result in an increase in uropepsin excretion, a fact which indicates the ability of the kidney to excrete pepsinogen, this observation lends additional support to the possible identity of uropepsin and pepsinogen.

If the above hypothesis is true, uropepsin may be regarded in the light of an excretion product of an endocrine rather than an exocrine secretion since, in this case, the product of glandular activity is being secreted directly into the blood stream rather than into the lumen of a gland. The endocrine activity of the peptic glands may be regarded somewhat analagous to a similar activity of the pancreatic acinar tissue. Although it is true that such cells secrete most of their enzyme products into the peancreatic ducts, some of these products (amylase, lipase) gain access directly into the blood and, in certain conditions, the amounts so absorbed become markedly increased.

\section{SUMMARY AND CONCLUSIONS}

1. A simple, reliable method has been described for the estimation of uropepsin excretion by man.

2. The stability of uropepsin has been confirmed and the fact that urine contains no inhibitors of uropepsin has also been demonstrated.

3. The proteolytic activity of urine at acid reactions can probably be ascribed primarily to the activity of uropepsin.

4. The presence of gastric secretory activity is essential for the formation of uropepsin.

5. Evidence is presented to indicate that uropepsin is derived from the direct secretion of pepsinogen into the blood stream by the secreting glands themselves and not from the reabsorption of pepsin from the lumen of the stomach.

\section{BIBLIOGRAPHY}

1. Brucke, E., Die verdauende Substanz im Urin. Sitzungsb. d. k. Akad. Wissensch. Math.-naturw. Cl., 1861, 43, 618 (quoted by Farnsworth, E. B., Speer, E., and Alt, H. L., J. Lab. \& Clin. Med., 1946, 31, 1025).

2. Bucher, G. R., Uropepsin: A review of the literature and report of some experimental findings. Gastroenterology, 1947, 8, 627.

3. Farnsworth, E. B., Speer, E., and Alt, H. L., The quantitative determination of a pepsin-like substance in the urine of normal individuals and of patients with pernicious anemia. J. Lab. \& Clin. Med., 1946, 31, 1025.

4. Frouin, A., Sur l'origine et le lieu de résorption de la pepsine urinaire. Compt. rend. Soc. de biol., 1904, 56, 204.

5. Bucher, G. R., and Ivy, A. C., Disappearance of uropepsin from the urine of gastrectomized cats. Am. J. Physiol., 1947, 150, 415.

6. Northrop, J. H., Kunitz, M., and Herriot, R. M., Crystalline Enzymes. Columbia University Press, New York, 1948, Ed. 2.

7. Folin, O., and Ciocalteu, V., On tyrosine and tryptophane determinations in proteins. J. Biol. Chem., 1927, 73, 627.

8. Freudenberg, E., and Buchs, S., Ueber die zweite Protease des Magensaftes, das Kathepsin. 'Schweiz. med. Wchnschr., 1940, 70, 249.

9. Eder, H., Bradley, H. C., and Belfer, S., The survival of cathepsin in autolysis. J. Biol. Chem., 1939, 128, 551.

10. Bergmann, M., A classification of proteolytic enzymes. Advances Enzymol., 1942, 2, 49.

11. Freudenberg, E., Die Aktivitätskurve des MagensaftKathepsins. Ann. Paediat., 1941, 156, 124. 